\title{
Progress in the prevention of chronic kidney disease in Latin America
}

\author{
Bernardo Rodríguez-Iturbe
}

The increasing incidence of chronic kidney disease (CKD) is a major public health concern in Latin America and was the subject of a meeting that took place in Villarrica, Chile, from 21 to 23 November 2005, under the sponsorship of the Latin American Society of Nephrology and Hypertension, the Chilean Society of Nephrology, and the International Society of Nephrology. The resulting consensus statement (Dirks JH et al. [2006] Ren Fail 28: 611-615) indicated that careful data collection, screening for risk factors, and initiation of public awareness campaigns were necessary to address the rising CKD rate. Recommendations were made that national health authorities include renal disease within the framework of prevention programs already implemented for other noncommunicable diseases.

Since this meeting, a committee chaired by Santos Depine and Rafael Burgos Calderón has developed models of renal health that can be combined with the disease surveillance and prevention programs already functioning in some countries (Depine $S$ and Calderón RB [2006] Ren Fail 28: 649-664). The committee has established official contact with 12 countries (Chile, Argentina, Uruguay, Venezuela, Colombia, Brazil, Paraguay, Bolivia, Mexico, Puerto Rico, Peru and Ecuador). As a result of these contacts, nine countries (Chile, Argentina, Uruguay, Venezuela, Colombia, Brazil, Paraguay, Bolivia and Mexico) have signed a memorandum of understanding to initiate renal disease prevention programs, and eight countries (Chile, Argentina, Uruguay, Venezuela, Colombia, Brazil, Paraguay and Puerto Rico) have introduced such programs.

Not surprisingly, the stage of implementation of the programs varies greatly. The most impressive results are those of the National Renal Healthcare Program in Uruguay (http:// www.nefrouruguay.com/content/mazzuchi. pdf), from which data have been reported for 1,362 patients followed up from 2004 ...strategies

aimed at

education

and raising

awareness

of CKD risk

factors are

bearing fruit

B Rodríguez-Iturbe is Professor of Medicine at the University Hospital of Maracaibo, Maracaibo, Venezuela.

Competing interests

The author declared no

competing interests.

www.nature.com/clinicalpractice doi:10.1038/ncpneph0811 to 2007. Patients enrolled in the program had had a glomerular filtration rate (GFR) $<60 \mathrm{ml} / \mathrm{min} / 1.73 \mathrm{~m}^{2}$, proteinuria $>300 \mathrm{mg} /$ day, or diabetes with microalbuminuria, for at least 3 months. Overall, $80 \%$ of patients had stage 1-3 CKD and 17\% had stage 1-2 CKD.

Inclusion in the prevention program resulted in improved blood pressure control, improved glycemic control, and reduced levels of cholesterol and triglycerides. Importantly, during the first 3 months after entry, mean GFR increased from $42.7 \mathrm{ml} / \mathrm{min} / 1.73 \mathrm{~m}^{2}$ to $48.2 \mathrm{ml} / \mathrm{min} / 1.73 \mathrm{~m}^{2}(P<0.05)$, and the rate of deterioration of renal function in patients with stage 2-3 CKD decreased from $-3.1 \mathrm{ml} / \mathrm{min} /$ year to $-0.13 \mathrm{ml} / \mathrm{min} /$ year.

The data also indicate that strategies aimed at education and raising awareness of CKD risk factors are bearing fruit. Among patients referred to the program in the period 2004-2005, $35.7 \%$ had systolic blood pressure $<140 \mathrm{mmHg}$ and $57.5 \%$ had diastolic blood pressure $<90 \mathrm{mmHg}$. Among patients who entered the program during the period 2006-2007, the corresponding values were $42.6 \%$ and $65.3 \%$, respectively. Furthermore, the rate of deterioration of GFR before program entry was $-0.44 \mathrm{ml} / \mathrm{min} / \mathrm{month}$ among patients who enrolled in the program during the period 2004-2005 and $-0.11 \mathrm{ml} / \mathrm{min} / \mathrm{month}$ among those who entered the program in the period 2006-2007.

Measurable improvements are possible if patients are enrolled early into prevention programs. The success of the Uruguayan program is, to my mind, even more remarkable given the geographic, economic and sociopolitical difficulties in reaching and educating family physicians and communities in Latin America. A recently awarded grant from the International Society of Nephrology is a well-deserved recognition of the efforts of the Uruguayan Renal Healthcare Committee and will no doubt strengthen its already impressive results. 